\title{
Wearable Sensors for Turning Assessment to Discriminate Frailty Syndrome Among Community- Dwelling Older Adults
}

Huei-Ling Chiu

Taipei Medical University

Chen-Ying Tsai

Soochow University

Yu-Lin Liu

National Chengchi University

Chun-Wei Kang

Taipei Medical University Hospital

Shu-Chun Lee ( $\nabla$ sclee@tmu.edu.tw )

Taipei Medical University

Research

Keywords: Cutoff point, Frailty, Wearable Sensors, Turning

Posted Date: August 26th, 2020

DOl: https://doi.org/10.21203/rs.3.rs-52872/v2

License: (9) This work is licensed under a Creative Commons Attribution 4.0 International License.

Read Full License 
The authors have withdrawn this preprint from Research Square 